\title{
How are Non-numerical Prognostic Statements Interpreted and are They Subject to Positive Bias?
}

\author{
Anne Moyer \\ Stony Brook University, anne.moyer@stonybrook.edu \\ Samantha Siess \\ StonyBrook University, samantha.siess@stonybrook.edu \\ Sumeet Bhinder \\ Stony Brook University, sumeet.bhinder@alumni.stonybrook.edu
}

Follow this and additional works at: https://commons.library.stonybrook.edu/psyc-articles

Part of the Psychology Commons

\section{Recommended Citation}

Moyer, A., Siess, S., \& Bhinder, S. (2017). How are non-numerical prognostic statements interpreted and are they subject to positive bias? BMJ Supportive \& Palliative Care, 0, 1-4. doi:10.1136/bmjspcare-2017-001331.

This Article is brought to you for free and open access by the Department of Psychology at Academic Commons. It has been accepted for inclusion in Department of Psychology Faculty Publications by an authorized administrator of Academic Commons. For more information, please contact mona.ramonetti@stonybrook.edu. 
How are non-numerical prognostic statements interpreted and are they subject to positive bias?

\author{
Anne Moyer, Ph.D., Samantha Siess, M.A., and Sumeet Bhinder, B.S. \\ Department of Psychology \\ Stony Brook University \\ Stony Brook, NY USA
}

Corresponding author:

Anne Moyer, Ph.D.

Department of Psychology

Stony Brook University

Stony Brook, NY 11974-2500

Tel: (631) 632-7811

Fax: (631) 632-7876

Email: anne.moyer@stonybrook.edu

Word count: 1,424

Number of tables: 1 


\begin{abstract}
Objectives: Frank, clear, communication with family members of terminally-ill or incapacitated patients has important implications for well being, satisfaction with care, and sound decision making. However, numerical prognostic statements, particularly more negative ones, have been found to be interpreted in a positively-biased manner. Less precise non-numerical statements, preferred by physicians, and particularly statements using threatening terms (“dying” vs. "surviving") may be even more subject to such biases.
\end{abstract}

Methods: Participants $(N=200)$ read non-numerical prognostic statements framed in terms of dying or surviving and indicated their interpretation of likelihood of survival.

Results: Even the most extreme statements were not interpreted to indicate $100 \%$ likelihood of surviving or dying, (e.g., "they will definitely survive," 92.77\%). The poorness of prognoses was associated with more optimistically biased interpretations but this was not, however, affected by the wording of the prognoses in terms of dying versus surviving.

Conclusions: The findings illuminate the ways in which commonly-used non-numeric language may be understood in numeric terms during prognostic discussions and provide further evidence of recipients' propensity for positive bias. 


\section{Objective}

A significant proportion of family members will serve as surrogate decision makers for an incapacitated loved one at the end of life, often without the assistance of advance directives.[1,2] There are many aspects of the decision making process that are burdensome for surrogates including uncertainty about prognoses, acknowledgment of the potential loss of the patient, and a responsibility to make the right decision.[3] The emotional aspects of the situation may impair surrogates' abilities to process information from health care providers as well as their reasoning ability.[4] Communicating effectively with family members of terminally-ill or incapacitated patients is challenging but important to their well-being and ability to make sound decisions. Providing clear, frank information at the end of life is related to satisfaction with medical care.[5] However, even direct, numerical prognostic statements (e.g., "a 95\% chance of dying”) are interpreted in a positively-biased manner by surrogate decision makers, particularly when prognoses are poor.[6] Furthermore, physicians report preferring subjective non-numerical communication about risk.[7] This propensity raises the question of the extent to which commonly-used, less precise non-numerical prognostic statements (e.g., "probably will not survive") may be even more likely to be interpreted in this way. Relatedly, the language and terms used in clinical encounters have important implications.[8] Because the framing of information in terms of positive and negative outcomes has been shown to influence the impact of messages, [9] it is also of interest whether conveying prognoses using words that are more threatening (i.e., "dying" versus "surviving") also may contribute to positive bias. Thus, this 
study examined the numerical interpretation of non-numerical prognostic statements conveying prognoses varying from good to poor outcomes framed in terms of dying versus surviving.

\section{Method}

Participants ( $N=200$ undergraduates, 139 female), were recruited through the Psychology Department subject pool. They had no prior experience as surrogate decision makers for a family member or a friend, to avoid any bias from past experience, and did not currently have a critically-ill family member or friend, to avoid unnecessarily upsetting individuals in such situations. They were asked to imagine that they were speaking to a physician about a patient or a parent being treated in an intensive care unit and asked, for example: "If the doctor says to you, 'I'm concerned that [they] will not survive,' what does that mean to you?' Participants were presented with 14 such non-numerical prognostic statements conveying varying levels of risk framed in terms of dying or surviving (see Table 1). They then indicated what they believed the likelihood of survival to be by making a mark on a $10 \mathrm{~cm}$ line depicting a scale from $0 \%$ to a $100 \%$.

Likelihood of survival was determined by measuring in millimeters from the leftmost reference point of $0 \%$ likelihood to the place where respondents marked the line. Deviation from the reference point of $100 \%$ survival was measured in millimeters to the mark for the positive prognostic statements (i.e., those that indicated that survival was likely) and from the reference point of $0 \%$ survival for negative prognostic statements (i.e., those that indicated that survival was unlikely). Degree of positive bias was determined by assessing the extent to which similarlyworded prognostic statements differing only in whether their outcome was positive or negative 
(e.g., "It is very likely that they will survive" versus "It is very unlikely that they will survive") deviated from their reference point of $100 \%$ survival or $0 \%$ survival, respectively.

Mean likelihood of survival was calculated for each statement to determine how non-numerical statements using such non-numerical terms as "definitely, probably, possibly" and phrases such as "concerned that" and "optimistic that" were interpreted numerically. Within-subjects $t$-tests were used to examine positive bias by testing whether the deviation of estimates from their reference point for similarly-worded prognostic statements was higher for those that conveyed negative (poor likelihood of survival) versus positive (good likelihood of survival) outcomes. ANOVA was used to determine whether there was an interaction of the effect of prognostic outcome (i.e., positive, or a good likelihood of survival, versus negative, or a poor likelihood of survival) and the framing of prognostic statements (conveyed in terms of dying versus surviving) such that the most positive bias would be observed in response to statements that convey a negative outcome and were phrased in a more threatening manner, that is, in terms of dying.

\section{Results}

Table 1 shows the average percent likelihood of survival estimated in response to the nonnumerical prognostic statements as well as the average deviation from their reference point, listed in order from the highest to the lowest likelihood of survival. 


\section{Table 1}

Mean (SD) Estimates of Likelihood of Survival for Prognostic Statements with Varying Levels of Risk and Framing in Terms of Dying versus Surviving

\begin{tabular}{|c|c|c|}
\hline Prognostic Statement & $\begin{array}{l}\% \text { Likelihood of } \\
\text { Survival } M(S D)\end{array}$ & $\begin{array}{l}\% \text { Distance from } \\
\text { Reference Point } \\
(0 \% \text { survival or } \\
100 \% \text { survival }) \\
M(S D)\end{array}$ \\
\hline [They] will definitely survive. & $92.77(10.97)$ & $7.23(10.97)$ \\
\hline It is very unlikely that [they] will die. & $89.25(11.74)$ & $10.75(11.74)$ \\
\hline It is very likely that [they] will survive. & $88.87(12.50)$ & $11.13(12.50)$ \\
\hline $\begin{array}{l}\text { I would say it's very unlikely that [they] will die. Saying } \\
\text { it another way, that means it's very likely that [they] are } \\
\text { going to survive. }\end{array}$ & $86.73(14.20)$ & $13.28(14.20)$ \\
\hline I'm optimistic that [they] will survive. & $81.16(17.93)$ & $18.84(17.93)$ \\
\hline I think [they] will survive. & $80.01(17.39)$ & $19.99(17.39)$ \\
\hline It is possible that [they] will not survive & $50.89(20.85)$ & $50.89(20.85)$ \\
\hline I'm concerned that [they] will not survive. & $35.65(23.41)$ & $35.65(23.41)$ \\
\hline [They] probably will not survive. & $24.54(20.38)$ & $24.54(20.38)$ \\
\hline It is very likely that [they] will die. & $23.78(22.60)$ & $23.78(22.60)$ \\
\hline It's very unlikely that [they] will survive. & $22.77(19.50)$ & $22.77(19.50)$ \\
\hline I don't think [they] will survive. & $22.24(20.27)$ & $22.02(20.27)$ \\
\hline $\begin{array}{l}\text { I would say it's very unlikely that [they] will survive. } \\
\text { Saying it another way, that means it's very likely that } \\
\text { [they] are going to die. } \\
\text { [They] will definitely not survive. }\end{array}$ & $20.17(19.01)$ & $20.17(19.01)$ \\
\hline
\end{tabular}


The highest estimate of likelihood of survival was in response to "They will definitely survive" $(92.77 \%)$ and the lowest was in response to "they will definitely not survive" $(18.82 \%)$. When these same frame/different outcome statements were compared, "[They] will definitely not survive" was interpreted significantly more optimistically, in that it was significantly further from its reference point of $0 \%$ survival, than "[They] will definitely survive" was from its reference point of $100 \%$ survival, $t(199)=6.59, p<.001$. Similarly, the statement, "I would say it's very unlikely that [they] will survive. Saying is another way, that means it's very likely that [they] are going to die" was further from its reference point of $0 \%$ survival than the statement "I would say it's very unlikely that [they] will die. Saying it another way, that means it's very likely that [they] are going to survive" was from its reference point of $100 \%$ survival $t(199)=3.96, p<$ .001. Finally, a 2 x 2 completely within-group ANOVA was used to examine the main and interactive effects of prognostic outcome (good versus poor) and framing (in terms of dying versus surviving) in response to the statements "It is very likely that [they] will die," "It is very unlikely that [they] will die," "It is very likely that [they] will survive," and "It is very unlikely that [they] will survive." There was no main effect of framing $F(1,199)=.12, p=.731$ and no interaction of framing and prognostic outcome $F(1,199)=.66, p<.001$. However, there was a main effect of outcome, again suggesting that statements that conveyed a poorer prognosis were more likely to be interpreted in a positively-biased manner $F(1,199)=61.01, p<.001$.

\section{Discussion}

In this study we asked respondents to estimate the likelihood of survival to non-numerical prognostic statements in order to provide a window on how recipients might understand an array of potentially vague descriptors of prognostic outcomes such as "possibly" and "probably" as 
well as more conclusive terms such as "definitely." For instance, a statement such as "It is possible that [they] will not survive" is interpreted to indicate approximately a 50/50 chance of survival. Interestingly, adding a more emotionally laden phrase "I am concerned that [they] will not survive" resulted in a much lower expectation (35.64\%) regarding the likelihood of survival. It is also interesting to note that even the most extremely positive and negative prognostic statements involving the phrases "will definitely survive" and "will definitely not survive" were not interpreted to indicate $100 \%$ likelihood of surviving or dying. This suggests that recipients' interpretations, even of the most rosy or dire predictions, are tempered to some degree. We found further that similarly-worded statements portraying poorer outcomes are more likely to be interpreted in positively-biased ways relative to less poor outcomes. This adds to previous findings [6] that numerical prognostic statements are subject to positive bias. This also demonstrates that these effects can occur even in individuals not currently under the duress of serving as a surrogate decision maker, and may represent a defensive phenomenon in response to negative information that operates more generally, and perhaps in the context of other types of medical consultations. Because numerical statements are also subject to bias, we do not suggest that subjective non-numerical prognostic descriptions be avoided, as recipients of risk information also encode verbatim representations of information as well as less formal gist representations.[10] Finally, we did not find evidence that this optimistic bias was affected by the wording of the prognostic statements in terms of dying versus surviving. Thus, this aspect of the language used in conveying prognoses may not be relevant to optimistically-biased interpretation of information. 


\section{Conclusion}

In addition to using suggested strategies such as inquiring about how much individuals wish to know about prognoses,[11] practitioners should be aware of the ways in which commonly-used non-numeric language may be understood in numeric terms during prognostic discussions, and check recipients' understanding during consultations for accuracy[12] and potential positive bias.

\section{Acknowledgements}

Conflicts of interest: None.

Ethics: Study approval was obtained from the Committee on Research Involving Human Subjects at Stony Brook University. 


\section{References}

1 Carlet J, Thijs, LG, Cassell J, Cox P, Hill N, Hinds C, Jorge M P, Reinhart K, Thompson, B.T. Challenges in end-of-life care in the ICU: Statement of the 5th International Consensus Conference in Critical Care: Brussels, Belgium, April 2003. Intensive Care Med 2004;30: 77084.

2 Shalowitz DI, Garrett-Mayer E, Wendler D. (2006). The accuracy of surrogate decision makers: a systematic review. Arch Int Med 2006;166:493-7. doi:10.1001/archinte.166.5.493.

3 Braun UK, Beyth RJ, Ford ME, McCullough LB. Voices of African American, Caucasian, and Hispanic surrogates on the burdens of end-of-life decision making. J Gen Intern Med 2008;23:267-74. doi:10.1007/s11606-007-0487-7.

4 Netzer G, Sullivan DR. Recognizing, naming, and measuring a family intensive care unit syndrome. Ann Am Thorac Soc 2014;11:435-41. doi:10.1513/AnnalsATS.201309-3080T.

5 Krawczyk M, Gallagher R. Communicating prognostic uncertainty in potential end-of-life contexts: experiences of family members. BMC Palliat Care 2016;15:59. doi:10.1186/s12904016-0133-4. 
6 Zier LS, Sottile PD, Hong SY, et al. Surrogate decision makers' interpretation of prognostic information: a mixed-methods study. Ann Intern Med 2012;156:360-6. doi:10.1059/0003-4819156-5-201203060-00008.

7 Gramling R, Irvin JE, Nash J, Sciamanna C, Culpepper L. Numeracy and medicine: key family physician attitudes about communicating probability with patients. J Am Board Fam Pract. 2004 Nov-Dec;17(6):473. doi: 10.3122/jabfm.17.6.473

8 Falkenstein A, Tran B, Ludi D, et al. Characteristics and correlates of word use in physicianpatient communication. Ann Behav Med 2016;50:664. doi:10.1007/s12160-016-9792-x

9 Garcia-Retamero R, Galesic M. How to reduce the effect of framing on messages about health. J Gen Intern Med 2010;25:1323-9. doi:10.1007/s11606-010-1484-9.

10 Reyna VF, Nelson WL, Han PK, Dieckmann NF.How numeracy influences risk comprehension and medical decision making. Psychol Bull 2009;135:943-73. doi: $10.1037 / \mathrm{a} 0017327$

11 Back AL, Arnold RM. Discussing prognosis: "How much do you want to know?" Talking to patients who are prepared for explicit information. J Clin Oncol 2006; 24: 4209-3. doi:

10.1200/JCO.2006.06.007 
12 Hutton D, Belkora J, Shachter R, Moore D. Are patients getting the 'gist' in risk communication? Patient understanding of prognosis in breast cancer treatment. J Cancer Educ 2009; 24: 194-9. doi: 10.1080/08858190902876452

\section{Comments}

This is an accepted manuscript of the BMJ Publishing group in BMJ Supportive \& Palliative Care on 4/21/2017, available online at: http://spcare.bmj.com/cgi/content/abstract/bmjspcare2017-001331. 